\title{
Trying to Fit a SQuare Peg in a Round Hole: IS COMMUNITY INTERPRETING JUST TOO BIG FOR Public Policy? The Canadian Experience
}

\author{
Angela Sasso \\ Critical Link \\ International \\ asasso06@gmail.com \\ Kiran Malli \\ Critical Link \\ International \\ kmalli@phsa.ca
}

A public policy that obliges the public sector to utilize the services of a properly trained community interpreter builds a framework for equity, and strengthens the interpreting industry. The current absence of political commitment leaves Community Interpreting vulnerable to shifts, and jeopardizes access to proper training for interpreters and access to public services for minority language speakers. Lack of public policy on access to health, legal and civil services for the minority language speakers impedes equity, and inhibits the delivery of effective public services. But is Community Interpreting just too big for public policy? This presentation will explore:

1) Brief evolution of community interpreting in the Canadian context

2) Models of public policy

3) The relationship between community interpreting and public policy

4) Whether public policy is a professional necessity

\section{Introduction}

Historically set against the backdrop of the more established field of conference interpreting, community interpreting in Canada has been struggling to find its position as a critical industry member since it started gaining a higher prominence in the early 1980's. Never really being able to weave itself into the fabric of government services, community interpreting has moved forward in a fragmented, yet oddly united fashion. While diverse sectors of public services have supported the claim that interpreting services are crucial to service provision, most notably healthcare and legal services, the overall field of community interpreting continues to remain just outside of the territory of public policy. But is public policy really what community interpreting needs? Or is community interpreting just too big to fit neatly into a public policy framework? Are our energies wasted in trying to engage governments rather than just getting on with the business of professionalization and service provision? This paper will explore the relationship between community interpreting and public policy and propose whether public policy is a professional necessity at this stage of evolution.

This paper will also look at some of the achievements made despite the lack of public policy, as well as the continued crisis in some sectors even though legislative platforms exist. Furthermore, the impact that maintaining a unified front through a collective of like-minded 
advocates has had on the industry and how the role of Critical Link International has managed to keep community interpreting on the agenda of health, legal and public services since its inception in 1995 will be explored.

\title{
2. A Brief History of Community Interpreting in Canada
}

In Canada we have taken a generalist approach to all interpreting activity that is done at a community level. Consequently this has meant that the umbrella of community interpreting has incorporated all interpreting activities that occur at a community level, regardless of sector (health, legal and public services). Legal, in this statement is assuming the broader definition encompassing both in and out-of-court interpreting activities. While court interpreting in Canada enjoys legislative protection under the Canadian Charter of Rights and Freedoms Section 14, and an accreditation process through the Canadian Translators, Terminologist and Interpreters Council (CTTIC), and their provincial affiliates, it is still at times considered a member of community interpreting. This association between court and community is frequently made because many of the same practitioners that work in court also work across all sectors at the community level. Moreover, court interpreting in Canada continues to wrestle with many of the same issues that other sectors of community interpreting are facing: issues of professional conduct, professional competencies and professional recognition as this paper will later demonstrate. The alliance between court and community is not intended to minimize the significant advances and sector specific challenges and realities of court interpreting, but instead to align resources and present a united front - an action that ultimately will benefit court as much as community interpreting.

\section{The Rise of Institutionalized Community Interpreting}

The most active definition of community interpreting that is used in Canada comes from the Healthcare Interpretation Network's National Standards Guide for Community Interpreting Services (2010).

\begin{abstract}
Bidirectional interpreting that takes place in the course of communication among speakers of different languages. The context is the provision of public services such as healthcare or community services and in settings such as government agencies, community centres, legal settings, educational institutions, and social services. Other terms have been used to describe community interpreting such as "public service interpreting", "cultural interpreting", "dialogue interpreting", "institutional interpreting, "liaison interpreting" and "ad hoc interpreting". However, community interpreting remains the most widely accepted term in Canada. ${ }^{2}$
\end{abstract}

Community interpreting activity chiefly gained a profile in the 1980's in Canada. The increased prominence coincided with a marked change in the face of Canadian immigration, which experienced a dramatic shift from mainly European immigrants in the first half of the

\footnotetext{
${ }^{1}$ A party or witness in any proceedings who does not understand or speak the language in which the proceedings are conducted or who is deaf has the right to the assistance of an interpreter. Available at Government of Canada. Justice Laws. http://lawslois.justice.gc.ca/eng/const/page-15.html

${ }^{2}$ National Standards Guide for Community Interpreting Services, Healthcare Interpretation Network, www.criticallink.org
} 
century to an influx of immigrants arriving from Asia, Africa, the Caribbean and Central and South America in the latter part of the century. In fact, countries in these regions were providing almost $90 \%$ of the immigrants to Canada by the 1990 's. ${ }^{3}$ As Canada welcomed newcomers from non-traditional source countries, workers in the service of assisting newcomers began to notice a growing need for language access to public, health and legal services. Initially the response was a typically ad-hoc one in which family and friends 'helped', an occurrence often seen in many other immigrant-based countries. ${ }^{4}$ This ad-hoc response was sustained by the aid organizations giving "help" as much as by professionals working within the various mainstream sectors that were attempting to work with nonEnglish or French speaking clients. Access to services through language support was a job done by any bilingual individual, regardless of how marginal their language skills.

The inflow of immigrants was not felt evenly across the country however. Immigrant settlement patterns during that post-1980 period generally favoured the provinces of British Columbia, Ontario and Quebec. ${ }^{5}$ In the early part of the $20^{\text {th }}$ century community-based responses, mainly through religious organizations and ethno-specific groups, sprung up to provide support to newcomers. As the century progressed, the sector began to see the development of a more coordinated effort through the implementation of non-profit services for immigrants and refugees. It was primarily through these non-profit organizations that community interpreting first gained a foothold. Initially assumed within the job duties of immigrant settlement workers or administered within a small projects portfolio, interpreting services were at the time run as bilingual or multilingual volunteer-based services, until the sector eventually recognized that the role of the interpreter was much more complex and dynamic than the existing approach afforded it. The emergence of community interpreting from the settlement services arena, rather than as a new branch of the interpreting profession itself (conference or court), explains the convoluted path that this division of interpreting has experienced. Settlement services are advocacy-based services. As community interpreting was assumed as a task within the settlement role, it too became imbued with the values of advocacy and cultural facilitation. Moving away from this to a more clearly defined description of interpreter as language facilitator proved challenging and caused considerable tensions within the sector.

In addition, the rise of community interpreting was definitely an "institution-led field"" - one in which the needs of the institutions were primary and the requirements of the profession secondary. This genesis has been the core of why community interpreting has not been able to find its status as a professional member of the industry, even though it is has been one of the fastest growing areas of interpreting ${ }^{7}$. This institution-led historical context is also the main reason why community interpreting has been assigned so many roles - from cultural navigator to cultural liaison to advocate to language facilitator. Institutions looked initially to the bilingual volunteer, and subsequently to the interpreter (once the role had gained more prominence the sector transitioned from volunteers to paid interpreters) to help them in understanding their "new" clients, the diversity of cultures and different styles of communication and engagement that they were facing.

${ }^{3}$ Larry Bourne and Rose Damaris, The changing face of Canada: The uneven geographies of population and social change; Canadian Geographer 04-01-2001

${ }^{4}$ Uldus Ozolins, Factors that determine the provision of Public Service Interpreting at http://www.jostrans.org/issue14/art_ozolins.pdf

5 Web site of Statistics Canada, http://www12.statcan.ca/English/census01/products/analytic/companion/etoimm/provs.cfm

${ }^{6}$ Uldus Ozolins, Factors that Determine the Provision of Public Service Interpreting

${ }^{7}$ Industry Canada, Community Interpreting in Canada, 2007 
Whereas increasing numbers of newcomers and a broadening of linguistic and cultural diversity significantly triggered the growth of the community interpreting movement, immigrants and refugees are not the only constituents in Canada facing language barriers in access to services

In her seminal report "Language Barriers in Access to Health Care", Dr. Sarah Bowen identified four constituencies who may face language barriers due to not having an official language:

1. First Nations and Inuit communities,

2. Newcomers to Canada (immigrants and refugees),

3. Deaf persons, and

4. Depending on location of residence, speakers of official languages (French and English) ${ }^{8}$

The identification of these four constituencies is an important note in the history of community interpreting in Canada because the alliance and dialogue between these four groups has been a central instigating force that has kept the community interpreting movement mobilized in Canada. While it has not always been a formal or even consistent coalition, the foundational work that has been done has been shared and leveraged across the language constituencies.

\section{Key Events in Canadian Community Interpreting}

The Canadian community interpreting movement has enjoyed significant accomplishments that have been instrumental in the ongoing development of the field. One of the most significant was the birth of Critical Link Canada (incorporated as Critical Link International 2010).

\footnotetext{
"The two hundred and fifty people who gathered at Geneva Park [Ontario, Canada] from June 1 to June 4, 1995 - there would have been more if we had had room for them - were conscious that they were attending an historic event in the evolution of professional interpreting. "Dr. Brian Harris ${ }^{9}$
}

Critical Link Canada was instrumental in gathering the voices and divergent experiences and opinions of practitioners, service providers, educators and policy makers across Canada (and ultimately internationally) to rally for the cause of community interpreting. Critical Link was, and is, an influential and a strategic partner in many of key events that have been the cornerstones in the evolution of community interpreting. And even when Critical Link was not present as a formal organization, the vision and commitment was always represented by the participation in significant events of Critical Link members. But most importantly, Critical Link has sought to bring together the four constituencies and has forged an alliance between visual and spoken language that has always been in development but which was solidified at the Vancouver, BC conference Standards and Ethics in Community Interpreting: Recent Developments in $1998 .^{10}$

\footnotetext{
${ }^{8}$ Sarah Bowen, Language Barriers in Access to Health Care, 2001

${ }^{9}$ Source: Critical Link International website, www.criticallink.org

${ }^{10}$ Source: Dr. Silvana Carr, Vancouver BC, 2014
} 
While Canada has adopted a generalist approach to community interpreting, many of the significant milestones have been achieved in either healthcare or court interpreting. In healthcare, stakeholders have collaborated on many initiatives that have laid the foundation for current events. The following list is intended as a sampling of these and is not a comprehensive list of activities:

1) The Healthcare Interpreter Partnership Project (British Columbia, 1996)

2) Healthcare Interpreter Services: Strengthening Access to Primary Care (National, 2006)

3) National Standard Guide for Community Interpreting Services (Ontario/National 2010)

4) Language Interpreter Service Program (Ontario, 2003)

5) Vancouver Community College - Healthcare Interpreting Program (British Columbia, 1996)

6) Regional Language Services (Winnipeg Regional Health Authority, Manitoba, 2009 and Provincial Health Services Authority, British Columbia, 2004)

\section{Community Interpreting in a Public Policy Approach}

The Merriam-Webster dictionary defines public policy as:

The governing policy within a community as embodied in its legislative and judicial enactments which serve as a basis for determining what acts are to be regarded as contrary to the public good

In their 2002 working paper titled Tools for Knowledge Exchange: Scanning Best Practices in Policy Research ${ }^{11}$, the authors present four characteristics that better position policy research for uptake by governments. These four are:

1) Reputation

2) Relevance

3) Credibility

4) Timing and Presentation

Reputation speaks to the obvious reputation of the organization conducting the research, which is essential, but it's the next three points of relevance, credibility and timing and presentation that seem to have more weight in the uptake of governments. For governments, the relevance of research is seen when it speaks to the challenges that governments face, and it must be relevant to the context of government. The context for Canada is an awareness of the federal/provincial jurisdictional considerations as well as the diverse needs and shifting priorities. Credibility refers to the presentation of an impartial approach; therefore any argument that is based in advocacy will lose credibility. In timing and presentation, the authors state that seeking windows of opportunity will further support any policy intention being judicious in the alignment of research findings and government priorities and in responding to government initiatives.

${ }^{11}$ Canadian Institute for Health Information, Tools for Knowledge Exchange: Scanning Best Practices in Policy Research, 2002 
While various initiatives in the field of community interpreting have been successful in obtaining government funding, the support has not always been consistent or ongoing. And while research evidence meets most of the characteristics above, community interpreting has still not secured a foothold in policy - apart from a few isolated cases that are sector and province-specific ${ }^{12}$. If the activities conducted to date have not secured government uptake in policy formation, then the question to be asked is 'why'? Why does the community interpreting agenda not move forward?

John Kingdon offers the identification of three process streams that must be in place in order for an issue to get on a political agenda. The first stream is the problem stream in which the problem is defined and enters into the public consciousness or narrative, this is agenda setting. Policy proposals will rise to the top of the agenda when the associated problem is recognized as important. This depends on how it is framed or brought to policy maker's attention (e.g., through data or focusing events); the second is the policy stream in which policy solutions are developed and proposed, generated, debated, revised, and put forth for serious consideration. More likely to be successful if perceived as technically feasible, compatible with policymaker's values, reasonable in cost, and appealing to the public; and the final is the politics stream which identifies the political realities that define the agenda (not the analysis). This stream refers to political factors that influence agendas, such as changes in elected officials, political climate or mood, and the voices of advocacy or opposition groups. ${ }^{13}$

Kingdon contends that all three streams must meet in order for an issue to be transformed into a policy. The process therefore is the evolution from problem to solution. The question for community interpreting is 'have we clearly framed the problem in a way that it will get noticed by policy makers?' The community interpreting movement has experienced progress, particularly in the area of healthcare interpreting. In a recent interview, Dr. Sarah Bowen states:

\begin{abstract}
I believe that one of the greatest achievements is that, to a large extent, we have been able to position ourselves within the context of 'evidence-informed decision making' - to use evidence to make the case for the importance of addressing language barriers. And I need to state that I am speaking strictly from a Canadian health care perspective here The research in this area has matured -15 or 20 years ago, we were relying on case studies to illustrate the risks of language barriers and using untrained interpreters. Today, however, we have a body of peer-reviewed research, using a range of research methods that is allowing us to measure the types and extent of impacts. ${ }^{14}$
\end{abstract}

Dr. Bowen also contends that now that we have established credibility in the need for interpreters in healthcare, we need to move on to the how. In Kingdon's model we are now facing the second stream of policy formation - which is the generation and proposition of solutions.

Now that the tide is turning, it has put us at another critical juncture - informing how, now that we know the risks, we should address language barriers. If health care providers are saying "yes, yes, we know that we need interpreters" and then rush in to fill the gap with untrained, unsupported individuals, or overly simplistic computer programs, we do not really move further ahead. The

\footnotetext{
${ }^{12}$ The Winnipeg Regional Health Authority in Manitoba and the Provincial Health Services Authority in British Columbia are two examples of sector and province-specific language access policies.

${ }^{13}$ Source: Dr. Liz Whynot - United Way Public Policy Institute presentation - 2104

14 Source: In Conversation with Dr. Sarah Bowen, The Link. Issue 13, June 2013, www.criticallink.org
} 
evidence must now support the "how" not only the "why". Health care typically leaps from "we have an issue" to "lets create a solution" without necessarily considering the most appropriate way to do this. So we have to turn our attention to informing the response to the identified problem presented by language barriers. If we fail to do so, we can expect that society will act, but not necessarily based on evidence of what is effective. ${ }^{15}$

While we have made great strides in healthcare interpreting, has the more general community interpreting made any advances in framing the broader issue?

\section{Court Interpreting and Public Policy}

While court interpreting is generally not considered community interpreting, it does bear comparison, chiefly because it a) often involves the same practitioners as those engaged in community and healthcare interpreting and b) it can be an interpreting activity that occurs at a community level. Exploring the current state of flux experienced by court interpreting in Canada can help illustrate how and what public policy contributes to the professional growth of an industry.

The right to an interpreter is protected by common law and secured within the Constitution of Canada - protected under Section 14 of the Charter of Rights and Freedoms. And the need for court interpreters continues to increase. ${ }^{16}$ Despite having such legislative teeth, the state of court interpreting in Canada is in a crisis. As a profession, court interpreting is facing numerous problems that are highlighting the need for better enforcement of standards and quality control measures. What exists in court interpreting is a strong public policy safety net - across federal and provincial jurisdictions - as well as certification through the Canadian Translators, Terminologists and Interpreters Council (CTTIC), a national body comprised of provincial and territorial affiliates. The CTTIC Board of Certification administers the court interpretation exam membership body. While the legislation and the certification are sound platforms for a profession, court interpreting is still rife with deeply rooted problems.

The Canadian Legal Information Institute (CanLII) database shows 86,496 results for litigation in which interpretation was an issue; more than 23,000 of these cases were at the appeal level. As of early 2010, CanLII's database included Supreme Court of Canada decisions from 1948 to the present, and the decisions of other Canadian courts beginning in some jurisdictions as early as 1990, and in others as late as 2008. Although the CanLII database cannot currently provide an accurate indication of the total number of cases involving interpreter issues from a particular decade, the database clearly indicates that there are significant numbers of cases in which the quality or accuracy of interpretation is an issue. ${ }^{17}$

As recently as 2007 a class action suit against the Government of Ontario for inadequate court interpretation services was initiated. Based on 2005 Ontario Superior Court of Justice summary conviction appeal regarding assault charges in which a stay of proceedings was ordered as a consequence of inaccurate interpreting at trial, the Court

15 Source: In Conversation with Dr. Sarah Bowen, The Link. Issue 13, June 2013, www.criticallink.org

${ }^{16}$ Annalisa Edoo, et al, White Paper on Quality Court Interpretation Services, 2010

17 ibid 
identified 'inconsistent standards of interpretation services provided in Ontario courts. ${ }^{18}$

The current state of court interpreting underscores the need for a thoughtful and purpose driven approach to the professionalization of community interpreting in Canada, inclusive of all service streams (health, legal and public sector), rather than pursuing the fast-track to public policy validation. Standardization, accreditation and working conditions are all in progress throughout spectrum of community interpreting.

Public policy did institute the right to qualified court interpreters, but it did not eliminate the complications that all of community interpreting experiences. Public policy is only one component, in a network of elements that must be in place in the evolution of the community interpreting profession. Court interpreting is an example of what may happen when other supports are not in place. So, what was missing? Was the mandate to professionalize an internal mandate or was it externally driven? And was public policy enacted in isolation of other realities facing the industry?

Are we waiting for public policy validation to define each aspect of community interpreting - legal, health, and public sector? Based on the Canadian experience of institutions dictating the role of the community interpreter, we must tread carefully as we have already borne witness to the problematic results in the early iterations of a Canadian community interpreter. We give up the power to define our role and our path to professionalization when we seek legislative legitimacy in isolation of other critical factors needing to be in place.

\section{Conclusions}

As we can see, the current absence of political will can leave community interpreting in a flux, but simply enacting or pursuing a public policy agenda will not necessarily cure community interpreting of its ills. Perhaps the question is not whether the industry needs public policy, but whether it is, indeed, needed at this point in our evolution. Time may be better spent on clearly defining the professional structure and process of training, certification, enforcement, membership and role definition - a progression articulately stated in Holly Mikkelson's 1996 article "The Professionalisation of Community Interpreting”.

Community interpreting in Canada has evolved as a generalist approach - it is the umbrella under which health, legal and public sector interpreting is positioned. However this configuration may be too broad for a public policy agenda. As we have seen, healthcare interpreting has made great advances in gaining attention, but it has been suggested that aligning interpreting with health inequities may better situate interpreting in healthcare for the public policy framework. And court interpreting has achieved a secure policy platform. So if policy recognition is what is desired, then perhaps fragmenting the field is an alternate approach. However we must consider the impact that may have on the community interpreting field in Canada. Is community interpreting served better in remaining united, and potentially becoming stronger as a profession, if all streams stand together (evidence has shown that as a unified body we have achieved significant milestones). Should we perhaps look to other professions that have cut across sectors and are not specialized in title or professionalization as role models?

18 R. v. Sidhu, 2005 CanLII 42491 (ON S.C.), accessed on February 19, 2014 http://www.canlii.org/en/on/onsc/doc/2005/2005canlii42491/2005canlii42491.html. 
If community interpreting is to have a hand in its own destiny, then clearly it must invest in a process that is defined by the practitioners, before the process is guided by external forces. While public policy is indeed important, perhaps is it best to first define the profession before the rush to legislation.

\section{References}

Fafard, Patrick. 2008. Evidence and Health Public Policy: Insights from Health and Political Sciences. National Collaborating Centre for Healthy Public Policy. Canadian Policy Research Networks. Ottawa. [Available at http://www.cprn.org/documents/50036_EN.pdf]

Canadian Population Health Initiative, Canadian Institute for Health Information. 2002. Tools for Knowledge Exchange: Scanning Best Practices in Policy Research. Ottawa. [Available at http://www.cprn.org/documents/50036_EN.pdf]

Industry Canada. 2007. Community Interpreting in Canada. [Available at www.criticallink.org]

Bowen, Sarah. 2001. Language Barriers in Access to Health Care. [Available at http://www.hc-sc.gc.ca/hcs-sss/pubs/acces/2001-lang-acces/index-eng.php]

Ozolins, Uldis. 2010. Factors that Determine the Provision of Public Sector Interpreting. [Available at http://www.jostrans.org/issue14/art_ozolins.pdf] 